\title{
EL SECRETO DE LAS COMUNICACIONES: PROBLEMAS ACTUALES
}

\author{
LUCRECIO REBOLLO DELGADO \\ Profesor Asociado de Derecho Constitucional \\ UNED
}




\section{SUMARIO}

InTRODUCCIÓN. 1. SecReto de LAS COMUNICACIONES. 2. ANÁlisis del CONCEPTO de COMUNICACIONES. 3. EL SECRETO COMO ELEMENTO ESENCIAL DEL DERECHO A LA INVIOLABILIDAD DE LAS COMUNICACIONES. 4. EL FUNDAMENTO DEL DERECHO A LA INVIOLABILIDAD DE LAS COMUNICACIONES. 5. LA INJERENCIA COMO ELEMENTO DELIMITADOR DE LA INCONSTITUCIONALIDAD. A) Relaciones entre particulares. B) En relación con el Estado. 6. LímiteS A LA VIGENCIA DEL SECRETO de LAS COMUNICACIONES. 7. EL SECRETO DE LAS COMUNICACIONES EN LA REGULACIÓN EUROPEA. 8. CONCLUSIONES DE LEGE FERENDA. 


\title{
EL SECRETO DE LAS COMUNICACIONES: PROBLEMAS ACTUALES
}

POR

\author{
LUCRECIO REBOLLO DELGADO
}

Profesor Asociado de Derecho Constitucional de la UNED

\section{INTRODUCCIÓN}

En la actualidad y en nuestro entorno social, pocas actividades o ámbitos de la vida escapan a los modernos ingenios de la tecnología o la telecomunicación. Ahora bien, el impacto de estas en la actividad humana no siempre presenta un carácter positivo, no en todas las ocasiones se utiliza en beneficio de un desarrollo social más justo y digno o en favor de las personas individualmente consideradas.

Los nuevos ingenios tecnológicos han tenido una aplicación concreta y de forma genérica beneficiosa para el hombre, baste recordar los modernos sistemas de comunicación, las aplicaciones médicas de la tecnología y otro gran número de avances que nos rodean e invaden nuestra vida cotidiana, haciéndola más placentera y en definitiva contribuyendo al bienestar social. De todos los ingenios quizás los que han introducido un cambio más vertiginoso, sobre todo por su expansión social, sean las telecomunicaciones.

La constatación de la realidad hasta aquí realizada, por somera, no pone de relieve la gran problemática que viene adjunta a esta evolución tecnológica. Sin querer hacer antropología o sociología, allí donde no se debe, sí hemos de recordar que el problema social, el conflic- 
to social no surge por las nuevas tecnologías, sino de la propia esencia del hombre. Existen formas primitivas de lesionar los intereses de otros, que están plenamente vigentes (robo, homicidio, etc.). La sociedad viene buscando soluciones a sus conflictos desde que el hombre convive en sociedad. Las nuevas tecnologías, por mucho que queramos estudiarlas desde distintas ópticas o desde las más variadas disciplinas, tienen un camino unívoco en la perspectiva jurídica. Todas han de partir de la persona y la relación entre ellas como elemento básico de su análisis. De lo contrario carecerian de basamento y sus conclusiones por muy racionales que fueran, no tendrían una aplicación práctica, ni contribuirian a solventar la problemática que su existencia y uso origina.

Desde su origen el hombre ha luchado por su paz, por su cotidianeidad, por su propiedad, por su ideología, por sus creencias o por su subsistencia, y en ello la inmensa mayoría de las veces el enemigo no eran los medios, las dificultades técnicas o los impedimentos físicos, sino que, por contra, se luchaba contra otras personas u otros grupos.

En resumen, la tecnología como tal no es un problema, es un medio puesto al servicio de la persona, de la que ésta puede realizar un uso debido, no lesivo, beneficioso o útil, o por contra, perjudicial. La decantación por una $u$ otra posibilidad depende en exclusiva del individuo, de la persona. Desde esta perspectiva, no compartimos aquellas opciones que manifiestan lo apocalíptico de las nuevas tecnologías, $\mathrm{ni}$ tampoco aquellas que se oponen a las mismas por considerarlas mecanismos diabólicos para el orden social. Igualmente, hemos de ser prudentes ante aquellas otras opiniones que ven en los modernos ingenios la panacea de todos los problemas que aquejan al hombre.

El conflicto es intrínseco al hombre, a la persona y a su relación con los demás y en esta interrelación es donde hemos de introducir los mecanismos para solventar los conflictos. No cabe ningún acercamiento a área alguna de conocimiento jurídico que no parta del ser humano y de su ubicación en un conjunto social.

La relación de las nuevas tecnologías con el derecho se incardina precisamente en la posibilidad que esta ciencia tiene de solventar el conflicto social que se origina. Definido el derecho como el mecanismo que resuelve los conflictos sociales les ilustrativa la definición romana del mismo: lustitia est constat et perpetuas voluntas ius suum quique tribuere), no nos queda otra alternativa que acudir a la norma para buscar posibles vías de solventar, o en todo caso, mejorar las relaciones 
humanas. De lo manifestado se extrae la virtualidad e importancia que en nuestra sociedad actual adquiere la regulación de las nuevas circunstancias, de las nuevas tecnologías. Su solución o no, afecta de forma directa al individuo, a su persona y derechos que le son inherentes, al bienestar y a la realidad social.

En los Estados que en la actualidad tienen un grado medio o alto de desarrollo industrial y tecnológico, la dinámica evolutiva de los derechos y libertades $y$ de forma genérica de la relación persona y derecho está produciendo un fenómeno de transición motivado por el propio desarrollo de la técnica. Así, observamos como se abre todo un mundo de nuevas relaciones entre individuos $y$ de estos con las organizaciones sociales institucionalizadas.

Estas circunstancias analizadas tienen hoy un claro ejemplo en el secreto de las comunicaciones. El reconocimiento constitucional y su inclusión como derecho fundamental, configuran el primer y más significativo referente en cuanto a la importancia de su garantía y ejercicio efectivo. Pero la significación de este derecho deviene a nuestro entender, no tanto de la facilidad de vulneración, que es un aspecto a tener en cuenta, y sí más bien de las consecuencias tan negativas que tiene la ausencia de garantía de forma genérica en la libertad y muy particularmente en el derecho a la intimidad.

Las siguientes páginas tienen como objetivo realizar un análisis jurídico que partiendo del conflicto existente y puesto de manifiesto, verifique la regulación relativa al secreto de las comunicaciones y obtenga conclusiones de ello. Se hace necesario por tanto, acudir al Derecho Comparado y a la interpretación que realizan tanto el Tribunal Europeo de Derecho Humanos como nuestro Tribunal Constitucional.

\section{SECRETO DE LAS COMUNICACIONES}

La pretensión del hombre de conocer las comunicaciones de otra u otras personas, ya sea íntimo o no el mensaje, ha existido siempre. Una manifestación de esta circunstancia podemos observarla en lo relativo a la correspondencia ${ }^{1}$ que tiene ya reconocimiento a nivel jurídi-

1 Es curiosa la lectura de la obra de Danan, l.: Histoire postal et libertés publiques. Le droit de libre communication des idées et opinions por voie de correspondence, LGDJ, París, 1965, y DE VAILLE, E.: Histoire Générale des postes françaises. PUF, París, 1947. 
co en 1790, año en que la Asamblea Nacional francesa establece el Decreto que configura la correspondencia como inviolable y suprime los denominados cabinet noir, que eran oficinas encargadas de investigar y controlar de forma sistemática y secreta la correspondencia. Estas prácticas las había puesto en funcionamiento e institucionalizado, con abundantes medios, Luis XIII y el Cardenal Richelieu.

El reconocimiento constitucional en España de la inviolabilidad de la correspondencia surge con la Constitución de 18692, pasando prácticamente con los mismos contenidos a la de $1876^{3}$. En la Constitución de 1931 se amplía en cierta medida la inviolabilidad, desapareciendo la concreción del medio, así se establece que "queda garantizada la inviolabilidad de la correspondencia en todas sus formas, a no ser que se dicte auto judicial en contrarion (art. 32). La Constitución de 1978 pretende incorporarse al grupo de normas fundamentales que protegen tanto frente a los modernos medios de comunicación como a los venideros, de esta forma establece en su art. 18.3 que "se garantiza el secreto de las comunicaciones...". Por contra realiza una precisión a nuestro juicio improcedente «... en especial, de las postales, telegráficas y telefónicas...». Hubiera sido mejor no haber delimitado los tipos de comunicaciones, sobre todo por lo vertiginoso de la evolución de éstos, y haber hecho una protección genérica del secreto de las comunicaciones o de las telecomunicaciones. Aún así, no debe extraerse del artículo que analizamos, que únicamente los citados son el objeto exclusivo de protección, sino que deben ser entendimos como una cláusula abierta que señala los más relevantes en la época en que se crea el texto constitucional. De esta forma, la interpretación del concepto comunicación ha de ser amplia y flexible. Con todo, el art. 18.3 supone un significativo avance con respecto a otras constituciones que referencian como único medio de comunicación el postal o el telegráfico; lo es igualmente con respecto al Convenio Europeo de Derechos Humanos (en adelante CEDH), que en su art. 8 reconoce únicamente la correspondencia como objeto de protección, siguiendo el ejemplo de otros textos internacionales como el art. 12 de la Declaración Universal

2 Art. 7: «En ningún caso podrá detenerse ni abrirse por la Autoridad gubernativa la correspondencia confiada al correo, ni tampoco detenerse la telegráfica.

Pero en virtud de auto de Juez competente podrá detenerse una y otra correspondencia, y también abrirse en presencia del procesado la que se le dirija por el correo".

3 Art. 7: "No podrá detenerse ni abrirse por la Autoridad gubernativa la correspondencia confiada al correo". 
de Derechos del Hombre, o el art. 17 del Pacto Internacional de Derechos Civiles y Políticos. Esta circunstancia ha motivado que la jurisprudencia del Tribunal Europeo de Derechos Humanos (en adelante TEDH) y la Comisión Europea hayan tenido que realizar un esfuerzo de delimitación e interpretación del término "correspondencia», con objeto de incluir en él otros medios de comunicación como son el telefónico, el telegrfáfico o el informático.

Por todo ello parece conveniente delimitar el significado de los términos que utiliza la Constitución y en concreto se hace imprescindible establecer qué entendemos en el art. 18.3 por comunicaciones y por secreto. De la atribución de significados e interpretación de estos conceptos depende en gran mediada el alcance de la garantía que la Constitución establece respecto de la inviolabilidad de las comunicaciones.

\section{ANÁLISIS DEL CONCEPTO DE COMUNICACIONES}

Un estudio del significado del término constitucional comunicaciones como objeto material de derecho ha sido realizado por Jiménez Campo ${ }^{4}$, quien establece tres delimitaciones del mismo:

«... Es en primer lugar un proceso, estos es, un procedimiento de relación significante entre personas que queda defendido por la norma frente a cualquier interceptación, suponga ésta mera retención o suspensión del curso de la comunicación o, en otro caso, además, el conocimiento por tercero de su contenido...".

Una segunda afirmación respecto del concepto comunicación es para el autor que venimos citando el «proceso de transmisión de mensajes, un proceso en cuyo curso se hacen llegar a otro expresiones del propio pensamiento articuladas en signos no meramente convencionales».

Por último establece Jiménez Campo que "sólo es comunicación, para los efectos del precepto que se examina, aquella que se mantiene a través de un determinado medio técnico, quedando fuera del ámbito de esta disposición - aunque no por ello desprovista de toda protección constitucional- las conversaciones directas o en persona».

4 JIMÉnEz CAMPO, J.: «La garantía constitucional del secreto de las comunicaciones", Revista Española de Derecho Constitucional, n. 20 de 1987, págs. 42 y siguientes. 
Por su parte, el Diccionario de la Real Academia Española de la Lengua entiende por comunicación en su acepción primera «Hacer a otro partícipe de lo que uno tiene". Una delimitación más válida juridicamente es la acepción segunda del citado texto cuando establece que es "Descubrir, manifestar o hacer saber a uno alguna cosa".

Requiere así la comunicación en esencia de cuatro elementos, un comunicador o emisor, un interlocutor o receptor, un medio a través del cual se realiza la comunicación, y por último, el contenido de ésta, que denominamos mensaje y que en ocasiones comprende en su significado los cuatro elementos citados.

Lo que el derecho protege es en su conjunto el proceso de comunicación, lo cual a su vez también plantea problemas de delimitación. De esta forma el derecho a una comunicación libre protegerá también los momentos previos y los finales de la misma. Como ha manifestado el TEDH ${ }^{5}$ "un obstáculo en la posibilidad misma de iniciar correspondencia representa la forma más radical de interferencia en el ejercicio del derecho al respeto de la misma; no es admisible considerar que tal obstáculo está fuera del campo de aplicación del art. 8, cuando no se discute que un simple control entra de lleno en dicho campon. Pero además, la protección del proceso comunicativo puede tener consecuencias más allá de éste. Como afirma Martín Morales ${ }^{6}$ la Constitución también protege el mensaje materializado en algún objeto físico, produciendo algunos efectos, "como la nulidad de la prueba ilícitamente obtenidan.

Por último debe excluirse del concepto constitucional de comunicación las conversaciones realizadas de forma directa o en persona, es decir sin la intermediación de algún elemento técnico, las cuales tienen su protección en el art. 18.1 CE, independientemente de que en la interceptación de la conversación se utilicen medios técnicos de captación de imagen o sonido. Nos recuerda Martín Morales ${ }^{7}$, que cuando aludimos a la necesidad de un soporte técnico "nos referimos al de la comunicación y no al de la interferencia, independientemente de que la interceptación de cierto tipo de comunicaciones requiere hoy en día una cierta sofisticación tecnológica».

5 STEDH caso Golder de 21 de febrero de 1975, reiterada con posterioridad en las SSTEDH de 25 de marzo de 1983, caso Silver, $y$ de 28 de junio de 1984, caso Campbell.

6 Martín Morales, R.: El régimen constitucional del secreto de las comunicaciones, Civitas, Madrid, 1995, pág. 47.

7 lbidem, pág. 52. 


\section{EL SECRETO COMO ELEMENTO ESENCIAL DEL DERECHO A LA INVIOLABILIDAD DE LAS COMUNICACIONES}

Lo relativo al concepto constitucional de comunicación es en esencia pacífico, tanto en la mayoría de los autores que han estudiado del art. 18.3 CE, como en la jurisprudencia. Pero no puede afirmarse lo mismo del término secreto, o mejor expresado, de la interpretación o significado que se atribuye al concepto constitucional de secreto en conexión con el concepto de comunicaciones. Se debe ello a que de la significación que demos a la palabra secreto, depende de forma directa el concepto y fundamentación del derecho a la inviolabilidad de las comunicaciones. Conviene por tanto realizar un resumen de las interpretaciones realizadas hasta ahora del término secreto referido a las comunicaciones, tanto de la doctrina como de la jurisprudencia.

Quizás la más antigua fundamentación de la inviolabilidad de la correspondencia sea la formulada por Santamaría de Paredes, quien entiende que ésta y el consiguiente secreto de las comunicaciones son contenidos de la libertad de comunicación, la cual está comprendida, con otras libertades, en lo que este autor llama el derecho de libertad 8 .

Por su parte Hauriou ${ }^{9}$ entenderá que existe un entronque común en la seguridad personal, tanto del derecho que estudiamos, como de la inviolabilidad del domicilio.

Para otros autores lo que se protege es tanto la libertad del pensamiento como la libertad de expresión. De esta forma la libertad de pensamiento tiene un destinatario individualizado, la libertad de expresión y de opinión tienen un destinatario genérico. Así lo argumenta Pace ${ }^{10}$, quien distingue entre el secreto de las comunicaciones y la libre emisión de pensamiento.

La Sentencia del Tribunal Constitucional 114/1984 revitaliza la conexión entre el secreto de las comunicaciones y la libertad de comunicación. En ella algunos autores fundamentan la inviolabilidad de las comunicaciones en el denominado derecho de libertad de las comuni-

8 Santamaria de Paredes, V.: Curso de Derecho Politico según la filosofia política moderna, la historia general de España y la legislación vigente, Imprenta Española, Madrid, 1913, págs. 170-171 y 174-175.

9 Hauriou, A.: Derecho Constitucional e instituciones politicas, Ariel, Barcelona, 1971, pág. 204.

10 PACE, A.: Problematica delle libertá costituzionall, Cedam, Padua, 1985, pág. 229. 
caciones ${ }^{11}$. Podemos resumir el contenido de la sentencia en la idea de que a través de la imposición a todos del secreto se protege la libertad de las comunicaciones, dado que aquél tiene en el art. 18.3 CE un carácter formal, a diferencia del exigible en el art. 18.1 que tiene un carácter material. De esta forma se presume formalmente iuris et de iure que todo lo comunicado es secreto, independientemente de cual sea su contenido material. Continúa manifestando el Tribunal Constitucional que el deber de no violar el secreto pesa sobre los terceros. Sin embargo, ex artículo 18.1, podría derivarse un posible «deber de reserva" para los comunicantes (no para los terceros) de contenido material12. Para Jiménez Campo el concepto de "secreto de las comunicaciones, es en la Constitución, rigurosamente formal. No se dispensa el secreto en virtud del contenido de la comunicación ni tiene nada que ver esta protección con el hecho -jurídicamente indiferente- de que lo comunicado entre o no en el ámbito de la privacy. Toda comunicación es, para la norma fundamental secreta, aunque sólo algunas, como es obvio, serán íntimas" ${ }^{13}$. Por ello y aunque parezca extraño, el art. 18.3 CE no ampara el contenido de las comunicaciones frente a la otra parte de la comunicación. No prohibe el citado artículo que el mensaje sea comunicado a un tercero por parte de algunos de los interlocutores, y por último, la cobertura del artículo citado no alcanza a la posibilidad de que uno de los interlocutores retenga de alguna forma lo comunicado (grabación). La obligación de reserva es siempre respecto de terceros que no intervienen ni son parte de la comunicación. El deber de no revelar el objeto de la comunicación se protege en virtud del art. 18.1 CE y no del art. 18.3 del mismo texto normativo.

\section{EL FUNDAMENTO DEL DERECHO A LA INVIOLABILIDAD DE LAS COMUNICACIONES}

Recientemente algunos autores ven inevitable la relación entre el secreto de las comunicaciones y el derecho a la intimidad. Así, Rodríguez Ruíz entiende que "el secreto de las comunicaciones es un

11 Jiménez CAmpo, J., en obra citada, págs. 35 y siguientes; PARdo Falcón, J.: "Los derechos del art. 18 de la Constitución española en la jurisprudencia del Tribunal Constitucional", Revista Española de Derecho Constitucional, n. ${ }^{\circ} 34$ de 1992, págs. 173 y 174.

12 STC 114/1984, fundamento jurídico $7 .^{\circ}$

13 Obra citada, pág. 41. 
aspecto de la intimidad que tiene fronteras conceptuales propias y puede, por tanto, ser reconocido como derecho autónomamente» 14 , aunque con posterioridad manifestará la autora que el derecho que estudiamos "debe ser tratado como un aspecto del derecho a la intimidad" ${ }^{15}$. También Martín Morales ${ }^{16}$ configura una relación significativa entre el derecho a la intimidad y el derecho al secreto de las comunicaciones, de tal forma que ve en éste último un instrumento de protección del primero. Entiende el autor citado que «así como el derecho a la intimidad se comporta constitucionalmente como garantía de la libertad, el derecho a la inviolabilidad de las comunicaciones funciona como una garantía de la intimidad, pero adquiriendo, además, la función de garantía de una gran variedad de derechos y libertades: contribuye a asegurar la libertad ideológica y política, garantiza la libertad de empresa, el secreto profesional, etc." ${ }^{17}$.

Tras el repaso a este panorama conceptual del derecho a la inviolabilidad de las comunicaciones conviene realizar algunas clarificaciones de las opiniones aquí resumidas, en la idea de buscar un fundamento constitucionalmente adecuado de la inviolabilidad de las comunicaciones:

1. Hemos de destacar la ubicación del texto que estudiamos (apartado 3 del art. $18 \mathrm{CE}$ ). Se incardina en un artículo que garantiza la intimidad personal y familiar entendida en sentido amplio. Además va contigüo a una de las manifestaciones más clásicas del derecho a la intimidad como es la inviolabilidad del domicilio. De esta forma, no cabe deducir otra pretensión por parte del constituyente que la de establecer un ámbito en el que el individuo sea el único capacitada para dar o no a conocer aquello que le afecta de forma personal y directa. Se pretende en todos los casos (artículos 18.1 a $18.4 \mathrm{CE}$ ) garantizar la dignidad de la persona, su libre desarrollo y configuración y se hace sobre el fundamento de la libertad del sujeto titular de estos derechos. La fundamentación común no implica que estemos ante los mismos objetos de protección jurídica, ni tampoco que deban utilizarse los mismos elementos de garantía, ni tampoco que no existan elementos diferenciales entre los derechos reconocidos en el art. $18 \mathrm{CE}$. Pero es claro que en todo él subyace una pretensión común, una misma raíz, que no es

14 Rodríguez Ruiz, B.: El secreto de las comunicaciones: tecnología e intimidad, McGraw Hill, Madrid, 1998, pág. 1.

15 Ibidem, pág. 23.

16 Obra citada, págs. 35 a 44.

17 Ibidem, pág. 44. 
otra que la protección de unos ámbitos de plena disposición por parte de la persona. Si el constituyente español hubiera querido garantizar la seguridad personal, sería lógica la inclusión del contenido del art. 18.3 en algún apartado del art. 17. De igual forma, si el trasfondo del secreto de las comunicaciones fuese la libertad de pensamiento o de expresión, hubiera sido en los artículos que a una y otra se dedican (art. 16 y 20) donde hubieran encontrado su mejor ubicación.

2. También es cierto, que los contenidos el art. 18.2 y $18.3 \mathrm{CE}$ son derechos con una entidad sustantiva y con un reconocimiento constitucional previo a la Constitución de 1978. De la misma forma que es una realidad el reciente surgimiento del derecho a la intimidad y su reconocimiento, por primera vez, en la vigente Constitución, lo es que ninguna de estas circunstancias es merecedora de ser tenida en cuenta para desligar tanto a la inviolabilidad del domicilio como al secreto de las comunicaciones del derecho a la intimidad. Pongamos como único ejemplo el ordenamiento jurídico alemán, en él existe quizás la doctrina más a tener en cuenta y la legislación más precisa, así como una extensa jurisprudencia al respecto del derecho a la intimidad. Por el contrario, la Ley Fundamental de Bonn no recoge como derecho a la intimidad. Esta deficiencia constitucional se soluciona acudiendo al contenido del art. 2.1 en el que se garantiza el libre desarrollo de la personalidad y a partir de él se configura un derecho tan fundamental en el ordenamiento jurídico que estudiamos, como es el derecho a la intimidad.

Por lo manifestado, entendemos que la constitucionalización del derecho a la intimidad viene a revitalizar y acomodar una serie de contenidos jurídicos ya existentes en nuestro ordenamiento jurídico y, además, suma otros nuevos. El resultado final es la pretensión de crear una protección integral de la persona basada en el respeto a su dignidad y libertad. Ello a nuestro juicio constituye un todo que conviene diferenciar en sus pretensiones y en su objeto, pero sin olvidar que obedece a un fin concreto y que posee una raíz común que no es otra que el derecho a la intimidad. En esta concepción no es impedimento alguno que determinados derechos tengan carácter instrumental respecto a otros, ni tampoco que tengan un ámbito concreto de proyección.

Como manifiesta Balaguer Callejon ${ }^{18}$ en "cualquier caso, intimidad y secreto de las comunicaciones no son términos equivalentes...

18 Balaguer Callejón, F.: Prólogo a la obra de Martin Morales, el régimen constitucional del secreto de las comunicaciones, Civitas, Madrid, 1995, pág. 13. 
(pero)... la identificación usual entre intimidad y secreto no es, sin embargo irrelevante...".

3. Del concepto de secreto utilizado por la Constitución en su art. 18.3 no puede extraerse otra conclusión que la presunción iuris et de iure de que lo comunicado es secreto. La presunción tiene de esta forma un carácter preventivo, que únicamente los intervinientes en la comunicación pueden romper. El resto de sujetos, sean privados o sean públicos, tienen la obligación, salvo en los casos constitucional o legalmente establecidos, de hacer efectiva aquélla presunción. De esta forma, independientemente del contenido material, la mera revelación, interceptación, detención, etc., de lo comunicado lesiona el derecho. Por tanto, lo que la inviolabilidad de la comunicación viene a establecer es un medio concreto de lesión del derecho a la intimidad. La especialidad viene constituida por la relevancia del medio empleado (la comunicación) pero el objeto de protección no deja de ser en última instancia la intimidad, o de forma más genérica la vida privada. Esto nos lleva a clarificar que tampoco es válida la conclusión doctrinal que configura al derecho a la intimidad como una garantía material, frente al derecho a la inviolabilidad de las comunicaciones como una garantía exclusivamente formal. La especialidad de la violación del derecho fundamental otorga contenido material al derecho a la inviolabilidad de las comunicaciones. Quizás la confusión estriba en que se entiende a la comunicación secreta porque es íntima, cuando en realidad la comunicación es secreta en todos los casos, independientemente de su contenido material.

\section{LA INJERENCIA COMO ELEMENTO DELIMITADOR DE LA INCONSTITUCIONALIDAD}

El art. 18.3 CE no establece delimitaciones conceptuales de las distintas formas de inviolabilidad de las comunicaciones, se limita únicamente a garantizar el secreto de las mismas. Esta tarea viene encomendada a la legislación ${ }^{19}$. La terminología pretende adecuarse a cada uno de los significados concretos y a las delimitaciones de aquéllos ilí-

19 La Ley de Enjuiciamiento Criminal habla de «detención de la correspondencia privada, postal y telegráfica" y de la "intervención de las comunicaciones telefónicas", así como de observación. Por su parte, el Código Penal utiliza los conceptos de apoderarse, refiriéndose a la correspondencia y de interceptación cuando a lo que alude es a las comunicación telefónica. 
citos reconocidos. Con todo, estas delimitaciones suelen producir diferencias de interpretación. Así viene ocurriendo en la actualidad con los términos "intervención" y "observación" 20 . Pese a esta circunstancia, está aceptado tanto por la doctrina como por jurisprudencia, la polivalencia en el ámbito de la inviolabilidad de las comunicaciones del término "interceptación", que se suele utilizar en sentido amplio y comprensivo por tanto, de cualquier forma de conocimiento de una comunicación ajena.

Desde una perspectiva constitucional no es tan significativo establecer la delimitación y significado concreto de cada unos de los vocablos utilizados por la legislación y sí lo es a nuestro entender, establecer si la conducta incumple o no el contenido constitucional. De esta forma, nos es imperativo averiguar qué tipo de actividad quiebra el derecho al secreto de las comunicaciones. Para realizar esta delimitación debemos extraer como primera conclusión relevante que la pretensión constitucional de establecer unos medios concretos de lesión del derecho (interceptación, revelación, reproducción, observación, detención etc.) no es taxativa, y sí por contra utiliza una concepción amplia del secreto de las comunicaciones. Ello se traduce en que lo relevante constitucionalmente es la injerencia de terceros ajenos a la comunicación, independientemente del medio o la forma para llevarla a cabo.

En esta delimitación de la lesión del contenido constitucional garantizado es significativa la clarificación del Tribunal Constitucional al respecto de los sujetos. Entiende que existen dos tipos de perjudicados; uno será el sujeto titular del derecho fundamental vulnerado, y otro $u$ otros serán aquellos que poseen un interés legítimo ${ }^{21}$. Es sujeto titular quien sufre de hecho la intromisión ilegítima y por lo tanto lo son todos los intervinientes en la comunicación, ya sean sólo emisores o receptores o ambas cosas de forma simultánea, y también independientemente del número de participantes en la comunicación. De esta forma, es sujeto titular tanto la persona física (extranjero o menores de edad) como la persona jurídica.

La legitimación surge normalmente después de consumado el hecho de la interceptación o mediante su constatación a través de un

20 Sobre la especial significación de ambos y su utilización pueden verse las obras de LóPEZ BARJA DE QUIROGA, J.: Las escuchas telefónicas y la prueba ilegalmente obtenida, Akal, Madrid, 1989, págs. 194 a 197, y la de AsEnCIo MeLlado, J. M.: Prueba prohibida y prueba preconstituida, Trivium, Madrid, 1989, pág. 100.

21 STC 214/1991, fundamento jurídico 3. ${ }^{\circ}$ 
perjuicio. No obstante, tanto el TC, como el TEDH han establecido que no se requiere siempre que la violación esté consumada. Así el TC entiende como vulneración de la inviolabilidad de las comunicaciones un acto de los poderes públicos antes de que éste hubiera alcanzado plena eficacia ${ }^{22}$. Por su parte la jurisprudencia europea va algo más lejos, admitie recursos interpuestos contra normas jurídicas de carácter general cuya mera existencia puede afectar algunos derechos de los destinatarios ${ }^{23}$. En el ámbito de la inviolabilidad de las comunicaciones la certeza de la vulneración tiene una dificultad añadida, dado que suele ser condición de éxito de la intervención legítima la de que sus víctimas no tengan conocimiento de ellas.

Será sujeto legitimado aquél tercero que aun no siendo parte directa de la comunicación, se vea afectado por la interceptación o revelación del contenido de aquélla. El amparo jurídico a que tiene derecho este tercero no se fundamenta únicamente en la protección que ofrece el art. 18.1 (derecho a la intimidad personal y familiar), sino que también se encuentra en el apartado tercero del mismo artículo. Se debe ello a que lo que la Constitución protege es el conjunto de la comunicación y no únicamente el mensaje o contenido.

Otro aspecto que conviene tratar en este apartado deviene de la extensión de la garantía constitucional de la inviolabilidad de las comunicaciones. En opinión de Jiménez Campo ${ }^{24}$, la catalogación del derecho que estudiamos como derecho público subjetivo hace de él "un derecho de defensa frente al Estado", ello implica que "de la disposición constitucional no nace para los particulares, de modo directo, deber alguno jurídicamente coercible, deber que puede existir -y existe, efectivamente, en nuestro ordenamiento-, pero a partir ya de disposiciones infraconstitucionales, penales y civiles". Se ratifica ello a juicio del autor que venimos citando en que el inciso final del artículo 18.3 "salvo resolución judicial» sólo adquiere sentido si se entiende frente a los poderes públicos.

Es admisible a nuestro entender la fundamentación de Jiménez Campo si atendemos al origen histórico del derecho que estudiamos. Tanto en el S. XIX como a principios del XX no cabe dar a la inviolabi-

22 STC 37/1989, fundamento jurídico $6 .^{\circ}$

23 Así ocurre en las SSTEDH de 22 de octubre de 1987, caso Dudgeon; en la de 26 de octubre de 1988, caso Norris, o en la de 22 de abril de 1993, caso Modinos.

24 Obra citada, págs. 56 y 57. 
lidad de las comunicaciones otra concepción que la de un puro derecho público subjetivo. Ahora bien, la incorporación a la Constitución de 1978 del secreto de las comunicaciones ha de ser entendida como un derecho fundamental vigente frente a todos, de lo contrario su eficacia y garantía dejan de tener el máximo nivel constitucional para verse apoyados en normas infraconstitucionales, lo cual desvirtúa en sí todo el sistema de reconocimiento y protección de los derechos fundamentales. El constante ensanchamiento de contenidos del derecho a la intimidad, y sobre todo su concepción expansiva, hacen de la inviolabilidad de las comunicaciones un derecho sometido a mayores y más fuertes medidas por parte del ordenamiento jurídico respecto del Estado que de los particulares, lo que no es obstáculo para la vulneración del derecho por ambos. De esta forma, nada dice Jiménez Campo de qué ocurre cuando el Estado actúa desprovisto de su potestas, y se somete al derecho privado como cualquier otro ciudadano. En estos casos, como es lógico, el Estado puede también lesionar derechos fundamentales.

Es doctrina asentada ya por el Tribunal Constitucional, que «los derechos fundamentales ostentan un doble carácter. En primer lugar los derechos fundamentales son derechos subjetivos, derechos de los individuos no sólo en cuanto derechos de los ciudadanos en sentido estricto, sino en cuanto garantizan un satatus jurídico o la libertad en un ámbito de la existencia. Pero al propio tiempo, son elementos esenciales de un ordenamiento objetivo de la comunidad nacional, en cuanto ésta se configura como marco de una convivencia humana justa y pacífica, plasmada históricamente en el Estado de Derecho y, más tarde, en el Estado Social de Derecho o el Estado Social y Democrático de Derecho...»25. Estas afirmaciones nos dan pie a distinguir dos ámbitos claramente diferenciables en el derecho a la inviolabilidad de las comunicaciones:

\section{A) Relaciones entre particulares}

Mediante las nuevas tecnologias se produce en ocasiones una sutil penetración en el ámbito de la persona. En otras ocasiones, la intromisión no es sutil ni leve, sino brutal y eminentemente lesiva.

Los nuevos ingenios técnicos y de comunicación puestos en la mano del hombre pueden ir de forma directa contra lo que denomina- 
mos derechos de la personalidad, es decir, contra aquellos derechos que la persona posee por el significativo hecho de serlo.

Por todo ello, hemos de realizar un acercamiento, aunque sea somero, a la fundamentación jurídica de los derechos de la personalidad, dado que ello nos dará el punto de partida y el objeto de cualquier regulación en el ámbito del derecho y sus relaciones con los modernos medios de comunicación.

Así, y partiendo de la idea de que "la finalidad genérica, que puede englobar a todas las categorías de derechos fundamentales, es favorecer el desarrollo integral de la persona humana, potenciar todas las posibilidades derivadas de su condición ${ }^{26}$, los derechos de la personalidad se manifiestan dentro de la legislación internacional y nacional como uno de los núcleos del reconocimiento y garantía de los derechos. El art. 10 de la Constitución Española se manifiesta en favor de una concepción iusnaturalista de la dignidad, es decir, entendida como la eliminación de la humillación humana. Hemos de tener en cuenta que la dignidad humana constituye no sólo la garantía negativa de que la persona no va a ser objeto de ofensas o humillaciones, sino que entraría también la afirmación positiva de pleno desarrollo de la personalidad de cada individuo. Como afirma Pérez Luño27, «el pleno desarrollo de la personalidad supone, de un lado, el reconocimiento de la total autodisponibilidad, sin interferencias o impedimentos externos, de las posibilidades de actuación propias de cada hombre; de otro, la autodeterminación que surge de la libre proyección histórica de la razón humana antes que de una predeterminación dada por la naturalezan. Pese a todo, no puede entenderse como un ámbito exento de limitaciones. De esta forma, y siguiendo con Pérez-Luño, "la dignidad humana supone el valor básico, fundamentador de los derechos humanos que tienden a explicitar y satisfacer las necesidades de la persona en la esfera moral» 28 .

El planteamiento constitucional de cualquier derecho fundamental se hace de forma genérica desde la perspectiva de su posible vulneración por el poder público. Pero en los derechos de la personalidad, se introduce una nueva posibilidad, consistente en la violación o lesión

26 Peces Barba, G.: Derechos Fundamentales, Facultad de Derecho de la Universidad Complutense de Madrid, Madrid, 1983, pág. 109.

27 Pérez luño, A. E.: Derechos Humanos. Estado de Derecho y Constitución, Tecnos, Madrid 1986, pág. 327.

28 Ibidem, pág. 318. 
de estos derechos por otra persona, por un ciudadano. La configuración teórica de esta realidad se ha plasmado en Alemania a través de la denominada Drittwirkung ${ }^{29}$. Esta teoría se manifiesta sumamente conflictiva, y en ella, el desarrollo constitucional es insuficiente, así como las aportaciones de nuestro Tribunal Constitucional. Sin embargo, es plenamente pacífico y está reconocido por el legislador y el Tribunal Constitucional que la virtualidad o eficacia de los mecanismos de garantía de los derechos fundamentales, son también aplicables a las vulneraciones realizadas por particulares. Prueba manifiesta y contundente de ello lo es el contenido del art. 9 de la Constitución Española y la Ley Orgánica 1/1982 de 5 de mayo. Ratifica la interpretación de estas normas la Sentencia del Tribunal Constitucional 231/1988, en cuyo fundamento jurídico primero se manifiesta de forma rotunda al respecto de que los derechos a la propia imagen, y a la intimidad personal y familiar, gozan de eficacia inter privatos y de acceso al amparo constitucional.

En la historia de los derechos fundamentales ha sido característica una tensión entre el individuo y el Estado motivada por la creciente internacionalización. Ello introduce no sólo un proceso de tensiones entre los individuos y el Estado, sino que en ella juegan también un papel relevante, además de los poderes intranacionales, los problemas de colisiones y conflictos entre individuos ${ }^{30}$. Por esta circunstancia no puede hablarse únicamente de relaciones entre individuos y Estados, sino también de relaciones entre individuos y órganos internacionales, entre éstos órganos y los Estados, y de los Estados entre sí, además de las relaciones interindividuales.

Los derechos fundamentales no siempre cabe entenderlos de forma exclusiva como limitadores del poder estatal, sino también, de los derechos de otros individuos. Esta circunstancia nos reconduce de forma inexcusable al papel del Estado en relación con los derechos fundamentales. En unos casos será negativo o de interferencia, pero en otros es positivo, lo que implica promoción y actuaciones para la garantía efectiva. En las relaciones entre el individuo y el Estado ha aparecido una nueva relación cuyos polos serían el Estado y la sociedad.

29 Drittwirkung des Grundrechte: efecto frente a terceros de los derechos fundamentales.

30 De Asís Rolg, R.: Las paradojas de los Derechos Fundamentales como limites al poder, Debate, Madrid, 1992, pág. 105. 
Como indica Bobbio, los derechos de libertad nacen contra el abuso del poder del Estado y para limitar este poder, mientras que los derechos sociales, para su protección efectiva, requieren un aumento de los poderes del Estado.

De esta forma, no podemos extraer otra conclusión que aquella que establece respecto de los modernos ingenios tecnológicos y significativamente los referidos a las telecomunicaciones, que son un medio que facilita la vulneración de los derechos del individuo (derechos de la personalidad), o que pueden ser utilizados con cierta impunidad frente a otros ciudadanos.

\section{B) En relación con el Estado}

La mecánica de funcionamiento de los Estados está concebida y adecuada a unas relaciones espacio-temporales dadas. Estas se ven en la actualidad, si no amenazadas, sí en términos de ser modificadas. Ante la importancia actual de la información y la tecnología, la necesidad de regulación, protección y prevención se ve multiplicada exponencialmente. Si a ello añadimos necesidades políticas, éticas, sociales, económicas, etc, constatamos también en un ámbito general o institucional, la existencia de una necesidad de solventar un problema social a través de la norma.

La universalización que supone la tecnología traspasa los límites y las prevenciones clásicas de los Estados, y ello tiene un aspecto positivo $y$ otro negativo. En el primero encuadramos las posibilidades de relación instantánea, un mayor conocimiento del mundo y una eliminación casi total de las barreras de espacio y tiempo. Esto supone un mayor acercamiento de la persona al Estado y una mejor relación entre ambos. Pero el aspecto que interesa al derecho es aquél en que surge el conflicto, o lo que es lo mismo, donde surge la necesidad de regulación. Estos aspectos coinciden plenamente con los negativos. La facilidad de comisión de delitos, de atentar contra los intereses generales o de lesionar ámbitos concretos de la convivencia social, entre otros, ha de ser tenida en cuenta por el Estado. Si a ello añadimos el inevitable desfase que las normas de derecho positivo ofrecen respecto a las transformaciones sociales, cuya evolución tecnológica es especialmente dinámica, nos encontramos con que el Estado no puede ser sujeto pasivo de los avances tecnológicos, dado que ello incidiría negativamente en la correcta actividad de las instituciones. 


\section{LÍMITES A LA VIGENCIA DEL SECRETO DE LAS COMUNICACIONES}

La Constitución de 1978 se aparta de nuestro constitucionalismo histórico en lo relativo al reconocimiento de la inviolabilidad de las comunicaciones, como hemos visto, por la especialidad de las posibilidades de vulneración de este derecho. Pero también lo hace porque suprime el único requisito que excepcionaba su vigencia y que no es otro que la motivación en la resolución del juez que autorizase la detención u observación de la comunicación.

No fue pacífico en la elaboración del texto constitucional la introducción del requisito de que la resolución judicial fuera motivada. Se justificó esta circunstancia en la imposibilidad de autorizar intervenciones de forma urgente, dado que la motivación obligaría al juzgador a dar audiencia contradictoria a las partes previa a la adopción de la resolución, posibilitando de forma inexcusable el recurso ${ }^{31}$. Además, en determinas intervenciones como las telefónicas, dejaría sin objeto la actuación, puesto que la eficacia de ésta se fundamenta en el desconocimiento por parte de aquellos a quienes se intercepta la comunicación.

A pesar de lo manifestado, el Tribunal Constitucional ha venido manteniendo la necesidad de la motivación de la resolución del juez que excepcione la vigencia de los derechos fundamentales. De forma concreta la STC 62/1982 de 15 de octubre establece en su fundamento jurídico $2 .^{\circ}$ que «toda resolución que limite o restrinja el ejercicio de un derecho fundamental, ha de estar motivada, de forma tal que la razón determinante de la decisión pueda ser conocida por el afectadon. Además, cabe argumentar que aunque la Constitución tiene como hemos visto aplicación directa, su excepción, como es el caso que estudiamos, no la tiene, por lo que se hace necesario un desarrollo legislativo que establezca la forma de llevar a la práctica por parte de los poderes públicos la intervención de las comunicaciones. De no acoger esta interpretación, sólo pueden darse dos opciones, a cual más negativa desde una perspectiva garantista de los derechos fundamentales. O se deduce la no obligatoriedad de motivación en la resolución judicial, o se deja en manos del juez establecer en qué casos se hace necesaria ésta y en qué casos no.

31 Diario de Sesiones del Congreso de los Diputados. Comisión de Asuntos Constitucionales y Libertades Públicas, n. ${ }^{\circ} 70$ de 1978, págs. 2520 y siguientes. 
Pese a todo, hay ocasiones en que la propia Constitución establece la exigencia de resolución motivada. Así ocurre por ejemplo en el art. 22.4 en el que la obligatoriedad de esta medida no tiene fundamento legal sino constitucional, a diferencia de lo que ocurre en los artículos 18.2, 18.3 o en el 20.5. Hemos de ser conscientes que la ausencia de delimitación puede constituirse en un elemento de abuso y arbitrariedad. De esta forma la configuración de nuestro ordenamiento jurídico deduce la obligatoriedad de la motivación no de la Constitución y sí de la legislación.

En contra de esta opinión se manifiesta Martín Morales ${ }^{32}$, para quien «existe base constitucional suficiente para mantener la exigencia de motivación de la resolución judicial del art. 18.3 CE... la motivación es aquí una exigencia del derecho a la tutela judicial efectiva consagrado en el art. 24.1 CE». Pero esta justificación, como se deduce del propio debate constituyente, no es válida a nuestro entender, dado que como hemos visto, si hubiera sido intencionalidad del constituyente haber introducido el requisito de la motivación en la resolución judicial lo hubiera hecho.

La delegación legislativa del constituyente no ha planteado problemas en lo referido a las comunicaciones postales o telegráficas, donde la Ley de Enjuiciamiento Criminal establece las garantías necesarias para excepcionar el cumplimiento constitucional (artículo 579). Por el contrario, el contenido de los artículos 579.1 y 579.2 del mismo texto, relativos a la intervención de comunicaciones telefónicas, son desde todo punto de vista insuficientes ${ }^{33}$ para una garantía eficaz del Derecho que estudiamos.

La Ley Orgánica 9/1984 de 26 de diciembre viene a dar solución al problema de la urgencia en la intervención de las comunicaciones con objeto de que la prevención y sanción de los delitos fuera la apropiada, y sobre todo viene a impedir que una laguna legal facilite la realización de actos delictivos. Por todo ello la citada norma prevé la adopción inmediata de la medida de intervención de la comunicación por la autoridad gubernativa, con posterior justificación a la judicial, de la necesidad de la medida, la forma de ejecución, así como el conteni-

32 Obra citada, pág. 105.

33 La constatación de esta necesidad ha sido reiterada por la totalidad de la doctrina, por todos, es interesante la lectura del artículo de LOPEZ BARJA DE QUIROGA, J.: "La urgente necesidad de reformar la regulación de las escuchas telefónicas". Actualidad Jurídica Aranzadi n. 359 de 1 de octubre de 1998. 
do de lo intervenido. De esta forma se da solución a un problema muy puntual que había dejado sin resolver la propia Constitución, pero quedan otros muchos sin resolver.

De forma casi alarmante ha puesto de manifiesto las deficiencias del ordenamiento jurídico español en el ámbito del secreto de las comunicaciones la STEDH de 30 de julio de 1998 (caso Valenzuela contra España). En su número 50 señala el TEDH que «algunas de las condiciones necesarias establecidas por el Convenio para asegurar la previsibilidad de la ley y garantizar en consecuencia el respeto a la vida privada y de la correspondencia no se encuentran incluidas en el art. 18.3 de la CE ni en las disposiciones de la Ley de Enjuiciamiento Criminal... Estas garantías no incluidas se refieren en particular a la definición de las categorías de personas susceptibles de ser puestas bajo escucha judicial, la naturaleza de las infracciones que pueden dar lugar a la orden judicial, la fijación de un límite a la duración de la ejecución de la medida, el procedimiento para elaborar los informes resumidos que contengan las conversaciones interceptadas, y la utilización y destrucción de las grabaciones realizadas".

Como puede apreciarse, el TEDH no viene sino a constatar una realidad jurídica, que no es otra que la insuficiente regulación legal en España de la excepción a la vigencia del derecho a la inviolabilidad de las comunicaciones y de forma concreta en lo relativo a las denominadas "escuchas telefónicas".

En alguna medida el Tribunal Constitucional en su sentencia 49/ 1996, de 26 de marzo había establecido ya la necesidad de unos requisitos mínimos tanto de la actuación judicial como de la resolución judicial, que reproducimos en la idea de que es la pauta que habrá de seguir de forma urgente el legislador para paliar la llamativa laguna legal en el desarrollo del art. 18.3 CE.

Se argumenta en el fundamento jurídico $3 .^{\circ}$ los requisitos para la intervención telefónica, resumiendo en tres las tareas que debe realizar el juez competente a la hora de establecer la medidas y que reproducimos dado su valor jurisprudencial:

“A) Estricta observancia, pues de la proporcionalidad. El principio de proporcionalidad se refiere no solo a la gravedad de la infracción punible, para justificar la naturaleza de la medida, sino también a las garantías exigibles de autorización judicial específica y razonada y de respeto en su realización de requisitos similares a los existentes en otro tipo de control de comunicaciones (ATC 340/1990). 
B) La motivación resulta necesaria porque sólo a través de ella se preserva el derecho de defensa y se puede hacer el necesario juicio de proporcionalidad entre el sacrificio del derecho fundamental y la causa a la que obedece (SSTC 160/1994, 50/1995 y 181/1995).

C) La legitimidad de la medida de intervención telefónica se condiciona en suma, a la consideración por el juez autorizante de su necesidad para la investigación de unos hechos determinados y con un específica tipificación penal, la resolución en que se acuerde debe mencionar expresamente las razones fácticas y jurídicas que apoyan la necesidad de la intervención, esto es, manifestar cuales son los indicios que existen acerca de la presunta comisión de un hecho delictivo grave por una determinada persona $y$, en función de esos indicios, proceder a su encaje en alguno de los tipos delictivos justificantes de la medida. Es imprescindible que la resolución judicial determine el objeto de la intervención: número o números de teléfonos y personas cuyas conversaciones han de ser intervenidas, que en principio deberán serlo las personas sobre las que recaigan los indicios referidos, el tiempo de duración de la intervención, quienes hayan de llevarlas a cabo y cómo, y los periodos en que haya de darse cuenta al juez para controlar su ejecución.

El control judicial efectivo, en el desarrollo y cese de la medida es indispensable para el mantenimiento de la restricción del derecho fundamental, dentro de los límites constitucionales. El juez que la autorice debe, en primer término, conocer los resultados obtenidos por la intervención, $y$ en el supuesto de que se produzca una divergencia entre el delito objeto de investigación y el que de hecho se investiga, debe adoptar la resolución que proceda, puesto que en otro caso (STEDH, caso Class de 6 de septiembre de 1978, caso Malone, de 2 de agosto de 1984, y caso Kruslin de 24 de abril de 1990), las intervenciones constituirían una injerencia de la autoridad pública en el ejercicio del derecho del afectado al respeto de su correspondencia y de su vida privada. Si un Tribunal sentenciador fundamenta su resolución condenatoria en pruebas obtenidas con violaciones de derechos fundamentales (sea por la policía, sea por los jueces de instrucción) la presunción de inocencia no ha de destruirse como derecho fundamental que es, con semejante material probatorion ${ }^{34}$.

Como puede comprobarse, las obligaciones que recaen sobre el juez que establece la medida no pueden limitarse únicamente a la au-

34 La cursiva es nuestra con objeto de resaltar los requisitos necesarios a juicio del Tribunal Constitucional para la constitucionalidad de la medida. 
torización de la misma sino que en todo caso, además de acordarla y de autorizarla, está obligado en todo momento a seguir su ejecución, pero ello no puede exigírse al juez sino es mediante norma.

Tras lo manifestado, quisiera traer como ejemplo de hacia dónde debe dirigirse la regulación de la intervención de las comunicaciones telefónicas, las reformas llevadas a cabo en la Ley Fundamental de Bonn en sus artículos 10 y $13^{35}$, de ellas podemos extraer algunas consecuencias positivas.

La Ley de 24 de junio de 1998 incorporó a la Ley Fundamental un segundo párrafo al artículo 10. El contenido exclusivo de éste artículo era: «El secreto de las correspondencia y de las comunicaciones es inviolable. Las limitaciones a este derecho sólo podrán establecerse en virtud de una ley". Se deduce del texto la implicita dificultad, al igual que en nuestra Constitución, de una garantía adecuada del bien jurídico protegido. Lo que se añade al art. 10 de la LFB es una delimitación de la excepcionalidad, que lo que en realidad hace es autorizarla en determinados supuestos. Así, el apartado segundo establece ahora que "En el caso de que la limitación tenga como finalidad la protección del orden fundamental liberal democrático o la garantía de la existencia de la Federación o de un Länd, la ley podrá establecer que no se informe a los afectados y que el control por los tribunales sea reemplazado por el efectuado por órganos creados al efecto por la representación popular». Puede comprobarse la semejanza de intencionalidades entre el artículo reproducido y la norma española de videovigilancia ${ }^{36}$, donde ante la inmediatez del delito puede autorizar la grabación el responsable regional de los Cuerpos y Fuerzas de Seguridad del Estado, quedando en manos de la Comisión la validez o no de lo grabado y sus consecuencias jurídicas, así como el destino de lo grabado.

Una segunda reforma constitucional ${ }^{37}$ aún más significativa tiene su fundamento en la lucha contra la criminalidad organizada, y es la del art. 13. Éste recogía de forma escueta en su primer apartado la inviolabilidad del domicilio. En el segundo se establece que «sólo los

35 Un amplio estudio de estas reformas puede verse en el artículo de GóMEz ORfanel, G.: "Domicilios y escuchas. La reforma constitucional alemana», Cuadernos de Derecho Público, n. 3 de 1998.

36 Ley Orgánica 4/1997 de 4 de agosto, por la que se autoriza la utilización de videocámaras a los Cuerpos y Fuerzas de Seguridad del Estado.

37 Aprobada por el Bundestag el 16 de enero de 1998. 
jueces y, en caso de que la demora comportara un riesgo, también los órganos que prevean las leyes podrán ordenar registros, que deberán realizarse siempre en la forma legalmente establecida". Pues bien, a este texto se le han añadido cuatro extensos párrafos. El primero de ellos, ahora apartado tercero del art. 13 de la LFB, autoriza mediante medios técnicos la vigilancia acústica de los domicilios, "cuando la investigación de los hechos resultase de otro modo desproporcionadamente dificultosa o sin perspectivas de éxito. Tal medida habrá de someterse a un plazo. Corresponderá conceder la autorización a un Tribunal integrado por tres jueces. En caso de que la demora supusiera un riesgo podrá concederla un único juez". En el apartado $6 .^{\circ}$ actual, se establece que «El Gobierno Federal informará anualmente al Bundestag sobre la colocación de medios técnicos... en tanto en cuanto se hubiese precisado intervención judicial. Una comisión elegida por el Bundestag efectuará el control parlamentario con base en tal información. Los Länder garantizarán un control parlamentario semejante".

Como puede verse, la norma alemana viene a adecuarse tanto a las necesidades sociales en relación a los modernos ingenios de la tecnología, como con las necesidades de seguridad jurídica y respeto al contenido esencial de los derechos fundamentales en una línea similar a la establecida por la jurisprudencia del TEDH.

Por último conviene referenciar, si bien no un límite, si una excepción constitucionalmente reconocida al derecho que estudiamos. Se trata del art. 55.1 CE, en el que debemos entender incluido el art. 18.3 también de la CE. Esta facultad se atribuye a la autoridad gubernativa, pudiendo disponer el control de las mismas. La garantía se desplaza de esta forma de la resolución motivada del juez a la autorización parlamentaria. Pero también esta excepción a la vigencia del derecho a la inviolabilidad del domicilio tiene límites, de tal forma que en ningún caso podrá acordarse si no es estrictamente necesaria, y además habrá de ser su aplicación proporcional a las circunstancias de que la originan.

\section{EL SECRETO DE LAS COMUNICACIONES EN LA REGULACIÓN EUROPEA}

El primer problema con el que nos encontramos en el secreto de las comunicaciones, es determinar la extensión del concepto. Como conocemos, el art. 8.1 del CEDH referencia la «correspondencia» como 
objeto de protección específica y no de forma genérica las comunicaciones $^{38}$.

Por su parte, el derecho comunitario originario, salvo en el art. 6.2 de la Declaración de $1989^{39}$, que establece el urespeto de las comunicaciones privadas", no conoce esta manifestación de la vida privada.

A pesar de ser abundante y temprana la jurisprudencia del TEDH relativa a la correspondencia ${ }^{40}$, normalmente versa sobre aspectos muy concretos (como el derecho a la inviolabilidad de la correspondencia de los presos, o la de éstos con sus abogados), aún así, se entiende extensivo el concepto de correspondencia a las comunicaciones telefónicas ${ }^{41}$, dada la incidencia y menoscabo que estas producen en los derechos de la persona y en su vida privada.

Es más, el juez Pettiti, en su opinión concordante del caso Malone, entiende que la finalidad última de cualquier legislación europea que proteja la vida privada, es evitar cualquier descubrimiento clandestino de lo dicho en privado, de lo que se deduce que la relación entre vida privada y escuchas es muy estrecha. Incluso, el TEDH va más allá de la propia escucha, entendiendo como violación del contenido del art. 8 cualquier medio, que sin consentimiento de los interesados, pueda determinar a quien se llama, cuándo y por cuanto tiempo ${ }^{42}$. En definitiva, el concepto correspondencia ha de ser entendido como comunicación, en el sentido más amplio que la ciencia permite hoy.

Por su parte, la jurisprudencia del TJCE se encamina sobre todo a la seguridad de las comunicaciones y documentación en el tráfico mercantil y a la prevención de la competencia desleal violando la correspondencia o realizando intromisiones ilegítimas en las comunicaciones de las personas jurídicas. Su fundamentación proviene del Reglamento 17/62, cuyos artículos 11 y 14.1 a) y b) configuran un ámbito de protección de la persona jurídica, que se ve ratificado en la STJCE

38 "Toda persona tiene derecho al respeto de su vida privada $y$ familiar, de su domicilio y de su correspondencian.

39 Declaración del Parlamento Europeo sobre Derechos y Libertades Fundamentales, adoptada por el Parlamento Europeo el 12 de abril de 1989.

40 SSTEDH, De Wilde y otros, A-12; Golder, A-18; Silver, A-61; Campbell y Fell, A-80; Boyle y Rice, A-131; Schöneberger y Durmaz, A-137; McCallum A-183 y Pfeifer, A-227, entre otras.

41 SSTEDH, Klas, A-28; Malone, A-82, Schenk, A-140; Kruslin A-176; Huving, A-176 y Andersson, A-226.

42 Caso Malone, A-82, n. ${ }^{\circ} 84$. 
AM \&S Europe Limited ${ }^{43}$. A pesar de ello, tanto la jurisprudencia, como la legislación en el ámbito comunitario relativa al secreto de las comunicaciones, es sumamente escasa.

Recientemente la Directiva 95/46/CE reconoce la protección de los datos personales frente a cualquier sistema de comunicación, y de forma concreta frente a la informática. Pero esta laguna normativa del Derecho Comunitario ha sido paliada en gran medida por la Directiva 97/66/CE del Parlamento Europeo y del Consejo de 15 de diciembre de 1997, cuya transposición se establecía como obligatoria para los Estados Miembros antes de que finalizara 1998. Esta Directiva requiere a aquéllos para garantizar la confidencialidad de las comunicaciones a través de redes públicas antes del día 24 de octubre del año 2000.

El objeto esencial de la Directiva es como establece su art. 1, armonizar las disposiciones relativas a protección de datos, de los distintos Estados, con objeto de garantizar «un nivel equivalente de protección de las libertades y de los derechos fundamentales y, en particular, del derecho a la intimidad, en lo que hace referencia al tratamiento de datos personales en el sector de las comunicaciones".

A continuación y como es útil costumbre jurídica en las regulaciones sobre nuevas tecnologías, se establecen las pertinentes definiciones, donde se utiliza un concepto global de comunicaciones, tanto de las presentes, como de las futuras.

Interesa destacar que el propósito de la Directiva radica en establecer las obligaciones y derechos tanto de abonados como de proveedores, en el ámbito de las telecomunicaciones. Además de ello, se regulan también obligaciones y derechos al respecto del tratamiento de datos de carácter personal. De esta forma, el proveedor de un servicio público de telecomunicaciones, está obligado a preservar la seguridad de sus servicios, y a garantizar la confidencialidad de las comunicaciones que son objeto del mismo. También se limitan y tasan, los datos que el proveedor, puede almacenar al respecto del usuario.

A pesar de toda la regulación citada no eran pocos los Estados Miembros que amparándose en el contenido del art. 8.2 del Convenio, posibilitaban de alguna manera las "escuchas ilegales» 44 .

43 De 18 de mayo de 1982 (155/79). Recueil. T. XXVIII., de 1982, págs. 1575 y ss.

44 Se posibilita la injerencia en las comunicaciones cuando "esté prevista por ley, y constituya una medida que, en una sociedad democrática, sea necesaria para la seguridad nacional, la seguridad pública, el bienestar económico del país, la 
En 1997, la STEDH relativa al caso Halford45, amplía el concepto de vida privada, y restringe en gran medida las excepciones de injerencia contenidas en el apartado segundo del artículo 8 . De esta for$\mathrm{ma}$, se incluyen en la vida privada las comunicaciones que se realizan desde el lugar de trabajo o desde otro cualquier lugar, sea éste público o privado. Se condena al Estado (Reino Unido) por no establecer los mecanismos necesarios que limiten la actividad de la policía en sus investigaciones. Lo significativo del caso, no es tanto la delimitación de comunicaciones privadas, sino la interpretación restrictiva que se realiza del concepto "necesario en una sociedad democrática". Queda sentado con ello el carácter expansivo del apartado primero del artículo 8 del Convenio, y el carácter restrictivo en su cumplimiento e interpretación del apartado segundo del mismo artículo. En el mismo sentido, el Tribunal en el caso Kopp ${ }^{46}$ ratifica esta jurisprudencia y entiende como violación del secreto de las comunicaciones la interceptación por parte de la policía suiza de las comunicaciones en el despacho de un abogado.

Conviene traer a comentario en este apartado la STEDH en el caso Valenzuela Contreras ${ }^{47}$, en él se pone de manifiesto de forma palpable la insuficiencia en el ámbito del secreto de las comunicaciones, de la legislación española. Además, el Tribunal establece una serie de criterios aplicables en la interceptación de conversaciones telefónicas que deduce del art. 8 del CEDH.

De esta forma, el límite "previsto por la ley" busca "en primer lugar que la medida incriminada tenga una base en el derecho interno. Sin embargo, esta expresión no se limita a remitir al derecho interno, sino que concierne también a la calidad de la ley; exige que sea compatible con la preeminencia del derecho, implicando así que el derecho interno debe ofrecer una cierta protección contra atentados arbitrarios de los poderes públicos a los derechos garantizados por el párrafo 1 . De esta exigencia deriva la necesidad de la accesibilidad de la ley para la persona implicada que por añadidura debe poder prever las consecuencias para ella".

Además, reconoce el Tribunal que "el peligro de arbitrariedad aparece con singular nitidez allí donde un poder de apreciación se ejer-

defensa del orden y preservación del delito, la protección de la salud o la moral, o la protección de los derechos y libertades de los demás».

45 De 27 de mayo de 1997.

46 STEDH de 25 de marzo de 1998.

47 STEDH de 30 de julio de $1998, n .^{\circ} 46$. 
ce en secreto. Cuando se trata de medidas secretas de vigilancia o de la interceptación de comunicaciones por las autoridades públicas, la exigencia de previsibilidad implica que el derecho interno debe emplear términos suficientemente claros para indicar a todos de manera suficiente en qué circunstancias y bajo qué condiciones habilita a los poderes públicos a tomar tales medidas. La existencia de reglas claras y detalladas en la materia es indispensable, tanto más cuanto que los procedimientos técnicos no cesan de perfeccionarse".

Por último, en el caso Lambert ${ }^{48}$ se pone de manifiesto como el requisito "prevista por la ley", no se constituye en el único necesario, ésta ha de tener lo que el Tribunal analiza como "calidad de la ley", $y$ debe ajustarse a la finalidad y necesidad ${ }^{49}$ de la injerencia.

\section{CONCLUSIONES DE LEGE FERENDA}

Como ha manifestado recientemente el Tribunal Constitucional en relación a la inviolabilidad de las comunicaciones, "la necesidad de tutela de este derecho es especialmente intensa... tanto porque dicho derecho...resulta fácilmente vulnerable, cuanto porque constituye una barrera de protección de la intimidad, sin cuya vigencia efectiva podrá vaciarse de contenido el sistema entero de los derechos fundamentales» 50 .

En el reconocimiento del derecho, ningún reproche puede realizarse al texto constitucional: ni por la ubicación del derecho, ni por la fundamentación del mismo, ni tampoco en cuanto al sistema o rango de las garantías y límites. Desgraciadamente no puede manifestarse lo mismo del desarrollo legislativo del precepto constitucional en el ámbito de las telecomunicaciones, y en especial de las telefónicas.

La vulneración de las comunicaciones, además de suponer una lesión de un derecho fundamental (no debemos de olvidar que ocasiona un sentimiento de inseguridad que tiene una repercusión directa tanto en la dignidad de la persona como el libre desarrollo de su personalidad) es también una restricción de la libertad del individuo con rasgos netamente perniciosos en la relación social. Está constatado el gran valor que el ciudadano otorga a la preservación de su intimidad y

48 STEDH de 24 de agosto de 1998, números 22, 25 y 28.

49 "Necesaria en una sociedad democrática».

50 STC 81/1998 de 2 de abril, fundamento jurídico 6 . $^{\circ}$ 
los aspectos negativos que la ausencia de vida privada produce en la relación social51.

Desde el punto de vista jurídico, las deficiencias se manifiestan esencialmente en la Ley de Enjuiciamiento Criminal. Tras la reforma llevada a cabo por la Ley Orgánica 4/1988 se regula por primera vez la intervención de las comunicaciones telefónicas, pero la insuficiencia del artículo 579 de la Ley de Enjuiciamiento es palpable, como ha constatado la jurisprudencia del Tribunal Europeo de Derechos Humanos. No plantea excesivo problema la aplicabilidad del apartado primero del citado artículo, referido a las comunicaciones postales y telegráficas. Por el contrario, el apartado segundo, y sobre todo tras el fenómeno de la denominada telefonía móvil adolece del mínimo de garantías constitucionales tanto en el propio texto como en su ejecución práctica. A ello hay que sumar algún error legislativo, como es el término "procesado" en lugar de hacer referencia al sujeto pasivo de la intervención telefóni$\mathrm{ca}^{52}$. Pero con todo, la carencia más grave de la Ley de Enjuiciamiento Criminal es la ausencia de la delimitación clara de la intervención de las comunicaciones y de la forma de llevarla a efecto.

Por su parte, el Código Penal, es quizás una norma más impropia de establecer un procedimiento de excepción a la vigencia de un derecho fundamental. Pese a ello su concepción del secreto de las comunicaciones es significativamente amplia y acude a la formulación correcta de los medios de intromisión ilegítima, así como a un establecimiento acertado del bien jurídico protegido, que no es otro que en último término del derecho a la intimidad.

51 Corrobora esta afirmación la Exposición de Motivos de la Ley Orgánica $7 / 1984$ cuando manifiesta que "La tipificación... viene exigida por imperativo de una sensibilidad democráticamente expresada ante la posibilidad, no prevista hasta ahora de manera explicita en nuestras leyes penales, de que se instalen con manifiesta ilicitud arbitrarias escuchas telefónicas".

52 Esta circunstancia fue puesta de manifiesto por el Tribunal Superior de Justicia de Valencia (Civil y Penal) en Auto de 10 de junio de 1991. Según éste, la intervención de las comunicaciones telefónicas, postales y telegráficas pueden acordarse en cualquier proceso por delito, y no sólo en los que se tramitan por sumario. Continúa manifestando la resolución, que lo que ocurrió es que al ser reformado el art. 579 de la LECr por la Ley Orgánica 4/1988, se mantuvo su redacción originaria en el párrafo primero, y lo que hizo fue trasladar las expresiones de éste al párrafo segundo. Si en el momento de promulgarse la LECr de 1882 sólo existía un proceso ordinario por delito, era lógico que se hablara de procesado. Cuando en 1988 ya existían otros dos procesos penales ordinarios por delito se mantuvo la terminología, a pesar de que en estos otros dos procesos no había ni auto de procesamiento ni, por tanto procesado (fundamento jurídico $3 . \%$. 
De esta forma, y como en otras ocasiones en el estudio de los derechos fundamentales, vemos cómo su garantía efectiva pende de la normativa procesal. Por ello se hace necesario, aunque sea de forma somera, constatar los mínimos constitucionales que esta regulación debe contener:

a) No puede entenderse el art. 579 de la LECr como una autorización genérica al poder judicial. Más bien al contrario, tal facultad debe ser interpretada como una herramienta dentro de un proceso penal. Como manifiesta Martín Morales "No es lógico que el juez estime que los datos aportados por el Ministerio Fiscal o por la Policía son suficientes para limitar un derecho fundamental $y$, sin embargo, no lo son para abrir un proceso penal. No debe ser la intervención judicial la que de origen a la causa, sino al revés, la causa debe preexistir» 53.

b) Es exigencia inexcusable en la apreciación de la medida de la intervención de las comunicaciones la ponderación de derechos. La injerencia o la excepción a la vigencia del derecho a la inviolabilidad de las comunicaciones es una medida grave, y en la misma medida habrá de serlo aquello que se pretende evitar, el bien jurídico protegido, o el delito que se pretende probar.

c) Consecuencia inexcusable de la proporcionalidad es la motivación de la resolución en la que se acuerda la intervención de las comunicaciones. Además habrá de detallarse en ella:

- las razones fácticas y jurídicas que apoyan la necesidad de la intervención.

- el objeto de la intervención (número o números de teléfono)

- personas sobre las que recaigan los indicios referidos

- el tiempo de duración de la intervención

- quienes han de ejecutarla

- por último, la forma de control por parte del juez de la medida

d) No puede deducirse otra interpretación de la Constitución más que aquella que hace pasar la excepción a la inviolabilidad de las comunicaciones por la expresa autorización del juez. De esta forma la intervención judicial no alcanza únicamente a la decisión de realizar la intervención, sino también a su control. Salvo la ejecución material, el

53 Obra citada, pág. 148. 